\title{
Association between changes in fat distribution and biomarkers for breast cancer
}

\author{
Willemijn A van Gemert1, Evelyn M Monninkhof1, Anne M May1, Sjoerd G Elias1, \\ Job van der Palen²,3, Wouter Veldhuis4, Maaike Stapper', Rebecca K Stellato5, \\ Jantine A Schuit6,7 and Petra H Peeters ${ }^{1,8}$ \\ 1Department of Epidemiology, Julius Center for Health Sciences and Primary Care, University Medical \\ Center Utrecht, Utrecht, the Netherlands \\ 2Medisch Spectrum Twente Hospital, Department of Epidemiology, Enschede, the Netherlands \\ ${ }^{3}$ Department of Research methodology, Measurement and Data analysis, University of Twente, \\ Enschede, the Netherlands \\ ${ }^{4}$ Department of Radiology, University Medical Center Utrecht, Utrecht, the Netherlands \\ ${ }^{5}$ Department of Biostatistics and Research Support, Julius Center for Health Sciences and Primary Care, \\ University Medical Center Utrecht, Utrecht, the Netherlands \\ ${ }^{6}$ Division of Public Health and Health Care, National Institute for Public Health and the Environment, \\ Bilthoven, the Netherlands \\ ${ }^{7}$ Department of Health Sciences and EMGO Institute for Health and Care Research, VU University, \\ Amsterdam, the Netherlands \\ 8MRC-PHE Centre for Environment and Health, Department of Epidemiology and Biostatistics, School of \\ Public Health, Imperial College, South Kensington Campus, London, UK
}

Correspondence should be addressed to E M Monninkhof Email:

e.monninkhof@umcutrecht.nl

\begin{abstract}
We assessed the associations between changes in total and abdominal fat and changes in biomarkers for breast cancer risk using data of the SHAPE-2 trial. In the SHAPE-2 trial, 243 postmenopausal overweight women were included. The intervention in this trial consisted of $5-6 \mathrm{~kg}$ weight loss either by diet only or exercise plus diet. After 16 weeks, we measured serum sex hormones, inflammatory markers, total body fat (measured by DEXA scan) and intra and subcutaneous abdominal fat (measured by MRI). Associations between changes in different body fat depots and biomarkers were analysed by linear regression using the study cohort irrespective of randomisation to make maximal use of the distribution of changes in fat measures. We found that a loss in total body fat was associated with favourable changes in free oestradiol, free testosterone, leptin and sex hormone binding globulin (SHBG). The loss of intra-abdominal fat was associated with a decrease in free testosterone, hsCRP and leptin, and an increase in SHBG. In the multivariable analysis, the best fitted models for the biomarkers free oestradiol, SHBG leptin and adiponectin included only total body fat. For free testosterone, this was subcutaneous abdominal fat, and for hsCRP and IL-6, only intra-abdominal fat change was important. For IL-6 and adiponectin, however, associations were weak and not significant. We conclude that, in our population of healthy overweight postmenopausal women, loss of fat at different body locations was associated with changes in different types of biomarkers, known to be related to risk of breast cancer.
\end{abstract}

\author{
Key Words \\ - body fat \\ - abdominal fat \\ - biomarkers \\ - postmenopausal women \\ - breast cancer risk
}




\section{Introduction}

Intervention studies suggest that body fat is an important mediator in the association between exercise and/or weight loss and biomarkers for risk of breast cancer in postmenopausalwomen. (McTiernan et al. 2004, McTiernan et al. 2004, Monninkhof EM et al. 2009, Friedenreich et al. 2010). This might be explained by the fact that adipose tissue produces inflammatory factors and adipokines and is an important source of sex hormone production after menopause. These factors are associated with an increased risk of cancer (Key et al. 2002, Kaaks et al. 2005, Guo et al. 2013, Niu et al. 2013, Macis et al. 2014).

Abdominal fat has been associated with several other chronic diseases (Ritchie et al. 2007, Lee et al. 2008, CepedaValery et al. 2011) and a higher incidence of premature mortality (Pischon et al. 2008), also independent of total body fat. Intra-abdominal fat, and not subcutaneous fat, is hypothesised to be most harmful for metabolic-related diseases (Bjorntorp 1997, Arner 1998, Tchernof et al. 2013). For postmenopausal breast cancer, the role of (intra-)abdominal fat is less clear (WCRF/AICR 2010). A limitation of previous research is that proxies such as body mass index (BMI) and waist circumference, respectively, were used for total and abdominal fat, or that a crosssectional design was used, which fails to investigate causal pathways. Two trials in postmenopausal women used computed tomography (CT) to investigate the effects of exercise-induced changes in abdominal fat on sex hormones and other breast cancer biomarkers. The effects of exercise on sex hormones and adipokines were moderated (McTiernan et al. 2004, Frank et al. 2005) or mediated (Friedenreich et al. 2011) by changes in total fat mass, but not by abdominal fat changes.

Here, we address the following research question: how are changes in total body fat and (intra)abdominal fat associated with biomarkers for breast cancer risk? We will investigate this in participants of the Sex Hormones And Physical Exercise (SHAPE)-2 trial (van Gemert et al. 2013, van Gemert et al. 2015, van Gemert et al. 2016).

\section{Materials and methods}

\section{Design and study population}

The SHAPE-2 study is a three-armed RCT conducted in 2012-2013 in the Netherlands. Postmenopausal women $(n=243)$ were randomised to a diet-induced weight loss intervention $(n=97)$, a mainly exercise-induced weight loss intervention (exercise combined with a small caloric restriction, referred to as diet plus exercise) $(n=98)$ or stable weight control group $(n=48)$. It was primarily designed to investigate the effect of equivalent weight loss with or without exercise on biomarkers of postmenopausal breast cancer risk. Details of the study design and registration are reported elsewhere (van Gemert et al. 2013). The study was approved by the ethics committee of the University Medical Center Utrecht. All participants provided written informed consent.

A random sample of women aged 50-69 years was recruited by mass mailings and media attention. Eligible women were postmenopausal; overweight/obese (BMI $\left.25-35 \mathrm{~kg} / \mathrm{m}^{2}\right)$; insufficiently active $(<2 \mathrm{~h} /$ week of $\geq 4$ metabolic equivalent activity); not using (sex) hormones; and not diagnosed with cancer or diabetes.

All women started with a 4-6week run-in period where a personalised standardised diet was prescribed, aiming stable weight and comparable macronutrient intake among participants. Hereafter, women were randomised. Women in the diet group were prescribed a caloric restriction of $3500 \mathrm{kcal} /$ week as compared to their estimated needs and habitual intake (i.e. standardised diet during the run-in period). They were asked to maintain their habitual physical activity level. Women in the diet plus exercise group followed an intensive 4-h/week combined endurance and strength exercise programme (energy expenditure of approximately $2530 \mathrm{kcal} /$ week). The exercise intervention was combined with a small caloric intake restriction of $1750 \mathrm{kcal} /$ week to ensure the intended weight loss in a short time frame. However, the emphasis was on exercise.

The goal of both intervention groups was to lose $5-6 \mathrm{~kg}$ of body weight within 14 weeks. The targeted total average weekly deficit for the diet plus exercise group is larger than that for the diet group (4280 kcal vs $3,500 \mathrm{kcal}$ ) to compensate for the gain in muscle mass (i.e. body weight) by the exercise programme. Women in the intervention groups ended the intervention period with 2-6 weeks weight maintenance wherein diet was adapted to stabilise body weight. Women in the control group were asked to maintain a stable weight.

The weight loss goals were obtained in the study. Body weight decreased, as compared to the baseline, by $4.9 \mathrm{~kg}(-6.1 \%)$ with diet and by $5.5 \mathrm{~kg}(-6.9 \%)$ with diet plus exercise. There was no change in body weight in the control group.
C 2017 Society for Endocrinology Printed in Great Britain
Published by Bioscientifica Ltd. 


\section{Fat measurements (determinant)}

At the baseline and after 16 weeks, body fat and lean mass were assessed by whole body dual energy X-ray absorptiometry (DEXA, Lunar Prodigy). Abdominal fat, comprising of subcutaneous abdominal adipose tissue (SAAT) and intra-abdominal adipose tissue (IAAT), was measured by magnetic resonance imaging (MRI, Philips, Ingenia 1.5 Tesla) with the use of the three-point IDEAL Dixon method (Dixon 1984). For every scan, three slices at lumbar levels L2-L3, L3-L4 and L4-L5 were analysed using Hippo Fat software (Positano et al. 2008) to obtain quantitative fat measures. The measured area $\left(\mathrm{cm}^{2}\right)$ of SAAT and IAAT were averaged for the 3 slices. Fat quantification was performed by two trained researchers (WvG and MS). The baseline and follow-up images of different intervertebral levels of each study participant were analysed by the same researcher. Inter-class correlation coefficients between the two researchers were $>0.99$ for SAAT and $>0.97$ for IAAT.

\section{Serum biomarker analyses (outcome)}

Blood was collected and serum was stored at $-80^{\circ} \mathrm{C}$ at the baseline and after 16 weeks. After completion of the trial, all samples were frozen and sent to the laboratory for analyses. Samples from one individual were analysed in the same batch.

Sex hormones Oestradiol and testosterone were determined by liquid chromatography-mass spectrometry (LC-MS), the reference standard for measuring sex steroids (Handelsman et al. 2013), in the University Hospital of South Manchester laboratory (https://www.uhsm.nhs. uk/services/pathology/). Free fractions of oestradiol and testosterone were calculated by using the total hormone levels, SHBG and a constant for albumin (Rinaldi et al. 2002). SHBG was measured by commercially available double-antibody radioimmunoassay kits (Roche Cobas: SHBG-03052001), performed in the SHO Velp laboratory (https://www.sho.nl/). Inter- and intra-coefficients of variation were $<10 \%$ for androgens (Thienpont et al. 2008), $<7 \%$ (Owen et al. 2014) for oestrogens and $<2 \%$ for SHBG. Technicians were blinded to study allocation.

A total of 24 samples of testosterone were below the lower limit of detection and were, therefore, assigned the value of this limit: $86 \mathrm{pg} / \mathrm{mL}$. Six oestradiol measures were outside acceptable postmenopausal values $(>42 \mathrm{pg} / \mathrm{mL})$ and were excluded (five at baseline, one at follow-up).

\section{Markers of inflammation and adipokines} Enzyme-linked immunosorbent assays (ELISA) were used to measure IL-6 (HS-600B, R\&D systems, Inc., Minneapolis, MN, USA), leptin (ME E-0300, LDN, Nordhorn, Germany) and adiponectin (RD195023100, BioVendor, Kassel, Germany). High sensitivity CRP (hsCRP) was measured by an immunoturbidimetric assay (CRP Gen.3, Cobas Roche). Analyses of these four biomarkers were performed at Labor Nord-West in Nordhorn, Germany (http://www. ladr.de/english). Intra-assay coefficients of variation were 2.4\% for IL-6, 3.3\% for CRP, 3.6\% for adiponectin and $2.5 \%$ for leptin. IL-6 and hsCRP values were below the limit of detection in five samples, i.e. $<0.1 \mathrm{pg} / \mathrm{mL}(n=2)$ and $<0.2 \mathrm{mg} / \mathrm{L}(n=3)$, respectively. These 5 samples were assigned this value of the lower limit of detection. One hsCRP measurement at follow-up that was $>25 \mathrm{mg} / \mathrm{L}$ was excluded from analysis as this may indicate a clinical inflammation or infection.

\section{Statistical analyses}

To address our research question, we used data of the SHAPE-2 trial. First, Pearson correlation coefficients were computed for change in the different fat measures and biomarkers. To examine the separate effects of total and abdominal (SAAT and IAAT) fat changes, univariable linear regression models were built for the separate changes in biomarkers (dependent variable). To address the issue of multiple testing, we chose a significance level (alpha) of 0.01 and reported corresponding 99\% confidence intervals $(99 \% \mathrm{CI})$.

To determine the independent contribution of each fat depot, multivariable regression models with the three fat determinants (total body fat, IAAT and SAAT) were fitted for each biomarker. Furthermore, stepwise forward selection was applied, i.e. we started with a null model with none of the fat measures included, and then the variables were added one at a time, until the $P$ value for adding another fat measure was too large $(P>0.1)$. Results are presented as standardised regression coefficients (St-b) which represent the association of a change in one standard deviation of the fat measure, with the change in standard deviations of the biomarker level. Explained variance ( $\mathrm{R}$ squared) of the models are also presented. We tested for interactions between the study group and changes in fat measures to see whether or not we should account for the delivered intervention in the models. Furthermore, since we analysed changes, time-invariant covariates do not confound the results and adjustment 
for these covariates was deemed unnecessary. All statistical procedures were performed using SPSS software version 2.0 .

\section{Results}

Table 1 shows the baseline characteristics of 243 women included in the SHAPE-2 study in total and divided by tertiles of body fat. The average age of women was 60 years, had a BMI of $29.2 \mathrm{~kg} / \mathrm{m}^{2}$ and a body fat percentage of $44 \%$. Women in the highest tertile of body fat have the highest levels of intra-abdominal fat, sex hormones and inflammatory markers and the lowest levels of SHBG in adiponectin. In total, 232 (95.5\%) of the 243 women completed the study.

\section{Changes in fat measures and biomarkers}

The mean change (SD) between the baseline and 16-weeks follow-up was for: body weight: $-4.2 \mathrm{~kg}$ (2.9); total body fat: $-3.5 \mathrm{~kg}(2.8)$; SAAT: $-34.8 \mathrm{~cm}^{2}$ (34.3) and IAAT: $-14.8 \mathrm{~cm}^{2}$ (20.3). The changes in different fat measures all correlated significantly with each other $(P<0.001)$ (Supplementary Table 1a, see section on supplementary data given at the end of this article). The mean change (SD) in biomarker levels between the baseline and 16 weeks was: $-0.02 \mathrm{pg} / \mathrm{mL}(0.07)$ for free oestradiol; $-0.35 \mathrm{pg} / \mathrm{mL}$ (0.87) for free testosterone; $+6.7 \mathrm{nmol} / \mathrm{L}(12.4)$ for SHBG; $-0.01 \mathrm{mg} / \mathrm{L}$ (4.29) for hsCRP; +0.09-pg/mL (1.74) for IL-6; $-10.6 \mathrm{mg} / \mathrm{mL}$ (13.9) for leptin; and $+0.01 \mathrm{ng} / \mathrm{mL}$ (1.23) for adiponectin. Correlation coefficients for changes in the different fat measures and biomarkers ranged between 0.15 and 0.35 (Supplementary Table 1b).

\section{Associations between changes in fat (distribution) and biomarkers}

Results of the univariable regression models, with 'change in a single fat measure' as the determinant and 'change in biomarker' as the outcome are presented in Table 2. We did not observe differences in these associations for the three trial arms (see supplementary Table 2). A loss in total body fat was statistically significantly associated with a decrease in free oestradiol, free testosterone and leptin, and increase in SHBG. Associations were strongest with leptin and SHBG: standardised regression coefficient (St-b) change per SD change in total body fat was 0.48 for leptin and -0.39 for SHBG, followed by free testosterone $(S t-b=0.27)$ and free oestradiol $(S t-b=0.18)$. The loss of subcutaneous fat was statistically significantly associated with the same biomarkers as we found for total body fat, with the exception for free oestradiol. The loss of

Table 1 Baseline characteristics of the SHAPE-2 study population in total and divided by levels of body fat.

\begin{tabular}{|c|c|c|c|c|}
\hline & $\begin{array}{c}\text { Total } \\
n=243\end{array}$ & $\begin{array}{l}\text { Lower tertile } \\
\text { Body fat } \\
n=81\end{array}$ & $\begin{array}{c}\text { Middle tertile } \\
\text { Body fat } \\
n=79\end{array}$ & $\begin{array}{l}\text { Highest tertile } \\
\text { Body fat } \\
n=80\end{array}$ \\
\hline \multicolumn{5}{|l|}{ Mean (standard deviation) } \\
\hline Age (years) & $60.0(4.8)$ & $60.3(5.0)$ & $60.7(4.6)$ & $59.1(4.6)$ \\
\hline Time since last menses (years) & $10.9(7.1)$ & $11.0(6.3)$ & $11.1(6.9)$ & $11.0(8.0)$ \\
\hline BMI $\left(\mathrm{kg} / \mathrm{m}^{2}\right)$ & $29.2(2.7)$ & $26.8(1.2)$ & $28.9(1.6)$ & $32.0(2.0)$ \\
\hline \multicolumn{5}{|l|}{ Body composition by DEXA } \\
\hline Total body fat (kg) & $34.0(6.2)$ & $27.4(2.5)$ & $33.5(1.6)$ & $41.1(3.4)$ \\
\hline Lean mass $(\mathrm{kg})$ & $43.0(4.0)$ & $40.7(3.4)$ & $43.5(3.4)$ & $44.8(4.1)$ \\
\hline \multicolumn{5}{|l|}{ Abdominal fat by MRI } \\
\hline Subcutaneous (SAAT, cm²) & $310(68)$ & $262(40)$ & $297(43)$ & $371(65)$ \\
\hline Intra-abdominal (IAAT, cm²) & $144(47)$ & $119(38)$ & $145(45)$ & $168(46)$ \\
\hline \multicolumn{5}{|c|}{ Geometric mean (95\% confidence interval) } \\
\hline Free oestradiol (pg/mL) & $0.09(0.09-0.10)$ & $0.07(0.06-0.08)$ & $0.09(0.09-0.11)$ & $0.12(0.10-0.13)$ \\
\hline Free testosterone $(\mathrm{pg} / \mathrm{mL})$ & $2.53(2.38-2.69)$ & $2.37(2.12-2.64)$ & $2.48(2.24-2.76)$ & $2.76(2.49-3.06)$ \\
\hline SHBG (nmol/L) & $48.6(45.9-51.4)$ & $53.6(48.3-59.5)$ & $51.6(47.2-56.3)$ & $41.1(37.3-45.3)$ \\
\hline hsCRP (mg/L) & $1.90(1.68-2.15)$ & $1.29(1.04-1.61)$ & $1.92(1.57-2.35)$ & $2.73(2.26-3.31)$ \\
\hline IL-6 (pg/mL) & $1.39(1.29-1.49)$ & $1.20(1.06-1.35)$ & $1.46(1.31-1.64)$ & $1.55(1.37-1.64)$ \\
\hline Leptin (ng/mL) & $29.4(27.4-31.6)$ & $21.4(19.4-23.7)$ & $28.3(25.7-31.2)$ & $43.4(38.4-49.0)$ \\
\hline Adiponectin (ng/mL) & 9.55 (9.19-9.93) & & $9.79(9.20-10.41)$ & $8.96(8.33-9.64)$ \\
\hline
\end{tabular}

Available baseline data: DEXA scan, $n=240$ (98.8\%); MRI scan, $n=239$ (98.4\%); SHBG, $n=242 ;$ free oestradiol, $n=236$ (five baseline values $>42$ pg/mL were excluded); free testosterone, $n=241$; CRP, $n=241$ (one follow-up value $>25 \mathrm{mg} / \mathrm{l}$ was excluded); IL-6, leptin, adiponectin, $n=242$. All other data was available for all women $(n=243)$.

BMI, body mass index; SAAT, subcutaneous abdominal adipose tissue; IAAT, intra-abdominal adipose tissue; SHBG, sex hormone binding globulin; hsCRP, high sensitive C-reactive protein; IL-6, interleukin 6. 
Table 2 Univariable and multivariable (full model and stepwise forward procedure) associations between the different fat depots and biomarkers for risk of breast cancer.

\begin{tabular}{|c|c|c|c|c|c|c|c|c|}
\hline & \multicolumn{4}{|c|}{ Univariable associations } & \multicolumn{3}{|c|}{ Multivariable associations } & \multirow[b]{2}{*}{$P$ value } \\
\hline & St-b & $99 \% \mathrm{Cl}$ & $\mathrm{R}^{2}$ & $P$ value & St-b & $99 \% \mathrm{Cl}$ & $\mathrm{R}^{2}$ & \\
\hline \multicolumn{9}{|l|}{$\Delta$ Free oestradiol } \\
\hline$\Delta$ Total body fat $(\mathrm{kg})$ & 0.18 & $0.01 ; 0.35$ & 0.03 & 0.007 & $0.19 *$ & $-0.08 ; 0.47$ & 0.03 & 0.013 \\
\hline$\Delta$ Subcutaneous abdominal fat $\left(\mathrm{SAAT}, \mathrm{cm}^{2}\right)$ & 0.11 & $-0.07 ; 0.28$ & 0.01 & 0.107 & -0.02 & $-0.27 ; 0.24$ & & \\
\hline$\Delta$ Intra-abdominal (IAAT, $\left.\mathrm{cm}^{2}\right)$ & 0.07 & $-0.10 ; 0.24$ & 0.01 & 0.291 & -0.02 & $-0.23 ; 0.19$ & & \\
\hline \multicolumn{9}{|l|}{$\Delta$ Free testosterone } \\
\hline$\Delta$ Total body fat $(\mathrm{kg})$ & 0.27 & $0.10 ; 0.44$ & 0.07 & $<0.001$ & 0.11 & $-0.15 ; 0.37$ & 0.08 & $<0.001$ \\
\hline$\Delta$ Subcutaneous abdominal fat $\left(\mathrm{SAAT}, \mathrm{cm}^{2}\right)$ & 0.26 & $0.09 ; 0.42$ & 0.07 & $<0.001$ & $0.16 *$ & $-0.08 ; 0.40$ & & \\
\hline$\Delta$ Intra-abdominal (IAAT, $\left.\mathrm{cm}^{2}\right)$ & 0.18 & $0.01 ; 0.34$ & 0.03 & 0.007 & 0.05 & $-0.14 ; 0.25$ & & \\
\hline \multicolumn{9}{|l|}{$\Delta$ SHBG } \\
\hline$\Delta$ Total body fat $(\mathrm{kg})$ & -0.39 & $-0.55 ;-0.23$ & 0.15 & $<0.001$ & $-0.34 *$ & $-0.59 ;-0.10$ & 0.16 & $<0.001$ \\
\hline$\Delta$ Subcutaneous abdominal fat (SAAT, $\left.\mathrm{cm}^{2}\right)$ & -0.26 & $-0.43 ;-0.10$ & 0.07 & $<0.001$ & 0.03 & $-0.19 ; 0.26$ & & \\
\hline$\Delta$ Intra-abdominal $\left(\right.$ IAAT, $\left.\mathrm{cm}^{2}\right)$ & -0.29 & $-0.45 ;-0.13$ & 0.09 & $<0.001$ & -0.12 & $-0.31 ; 0.07$ & & \\
\hline \multicolumn{9}{|l|}{$\Delta$ hsCRP } \\
\hline$\Delta$ Total body fat $(\mathrm{kg})$ & 0.13 & $-0.04 ; 0.30$ & 0.02 & 0.047 & 0.03 & $-0.23 ; 0.28$ & 0.04 & 0.025 \\
\hline$\Delta$ Subcutaneous abdominal fat $\left(\mathrm{SAAT}, \mathrm{cm}^{2}\right)$ & 0.12 & $-0.06 ; 0.29$ & 0.01 & 0.083 & 0.03 & $-0.21 ; 0.26$ & & \\
\hline$\Delta$ Intra-abdominal $\left(\right.$ IAAT, $\left.\mathrm{cm}^{2}\right)$ & 0.19 & $0.02 ; 0.36$ & 0.03 & 0.005 & $0.17 *$ & $-0.03 ; 0.37$ & & \\
\hline \multicolumn{9}{|l|}{$\Delta$ IL-6 } \\
\hline$\Delta$ Total body fat $(\mathrm{kg})$ & 0.06 & $-0.12 ; 0.24$ & 0.01 & 0.370 & -0.13 & $-0.40 ; 0.13$ & 0.04 & 0.040 \\
\hline$\Delta$ Subcutaneous abdominal fat $\left(\mathrm{SAAT}, \mathrm{cm}^{2}\right)$ & 0.13 & $-0.44 ; 0.30$ & 0.02 & 0.055 & 0.15 & $-0.09 ; 0.40$ & & \\
\hline$\Delta$ Intra-abdominal (IAAT, $\left.\mathrm{cm}^{2}\right)$ & 0.16 & $-0.02 ; 0.33$ & 0.02 & 0.018 & $0.16^{*}$ & $-0.04 ; 0.37$ & & \\
\hline \multicolumn{9}{|l|}{$\Delta$ Leptin } \\
\hline$\Delta$ Total body fat $(\mathrm{kg})$ & 0.48 & $0.33 ; 0.63$ & 0.24 & $<0.001$ & $0.43 *$ & $0.21 ; 0.66$ & 0.24 & $<0.001$ \\
\hline$\Delta$ Subcutaneous abdominal fat $\left(\mathrm{SAAT}, \mathrm{cm}^{2}\right)$ & 0.34 & $0.18 ; 0.50$ & 0.11 & $<0.001$ & 0.02 & $-0.19 ; 0.23$ & & \\
\hline$\Delta$ Intra-abdominal (IAAT, $\left.\mathrm{cm}^{2}\right)$ & 0.28 & $0.12 ; 0.45$ & 0.08 & $<0.001$ & 0.04 & $-0.13 ; 0.22$ & & \\
\hline \multicolumn{9}{|l|}{$\Delta$ Adiponectin } \\
\hline$\Delta$ Total body fat $(\mathrm{kg})$ & -0.14 & $-0.31 ; 0.03$ & 0.02 & 0.032 & $-0.12 *$ & $-0.38 ; 0.13$ & 0.03 & 0.087 \\
\hline$\Delta$ Subcutaneous abdominal fat $\left(\mathrm{SAAT}, \mathrm{cm}^{2}\right)$ & -0.13 & $-0.30 ; 0.04$ & 0.02 & 0.045 & -0.03 & $-0.26 ; 0.21$ & & \\
\hline$\Delta$ Intra-abdominal (IAAT, $\left.\mathrm{cm}^{2}\right)$ & -0.11 & $-0.28 ; 0.06$ & 0.01 & 0.091 & -0.04 & $-0.23 ; 0.16$ & & \\
\hline
\end{tabular}

A significance level of $<0.01$ was chosen considering multiple testing. Therefore, corresponding $99 \%$ confidence intervals $(99 \% \mathrm{Cl})$ are presented $\Delta$ : change, defined as follow-up minus baseline measurement.

$\mathrm{St}-\mathrm{b}$ is the standardised regression coefficient from a linear regression model that represents the standard deviations (sD) change in biomarker level per 1 SD change in fat measure. Eg. as change in total body fat increases with 1 SD, the change in free oestradiol increases with 0.22 sDS.

*The fat measure marked with an asterix is the variable that is retained in the model after stepwise forward selection is applied. In each case the procedure stopped after only one fat measure was added.

$\mathrm{R}^{2}$ : percentage of variance in the dependent variable that is explained by the independent variable(s). For the multivariable models, the R-squared values are for the models with all three fat measures included, and not the model resulting from the stepwise procedure."

SHBG, sex hormone binding globulin; hsCRP, high sensitive C-reactive protein; IL-6, interleukin 6

intra-abdominal fat was statistically significantly associated with a decrease in free testosterone, hsCRP and leptin, and an increase in SHBG. The strongest associations were found for SHBG (St-b=-0.29) and leptin (St-b=0.28); followed by free testosterone $(S t-b=0.18)$ and hsCRP $(S t-b=0.19)$. None of the changes in fat depots was statistically significantly associated with changes in IL-6 and adiponectin.

In the multivariable analyses, using the stepwise forward selection method, for the biomarkers free oestradiol, SHBG, leptin and adiponectin changes in total body fat appeared most important (Table 2). For free testosterone, changes in subcutaneous abdominal fat were most important. However, for hsCRP and IL-6, intraabdominal fat change contributed most. For IL-6 and adiponectin, however, the associations with the fat depot retained in the stepwise forward procedure were weak and not statistically significant. The explained variance $\left(\mathrm{R}^{2}\right)$ of the multivariable models including all three fat measures was highest for leptin $\left(\mathrm{R}^{2}=0.24\right)$ and SHBG $\left(\mathrm{R}^{2}=0.16\right)$. The explained variances for the other biomarkers are low (range 0.03-0.08).

\section{Discussion}

In our population of healthy overweight postmenopausal women, we found that loss of fat at different body locations was associated with changes in different types of biomarkers, known to be related to risk of breast cancer. None of the changes in fat depots was statistically significantly associated with changes in IL-6 
and adiponectin. Reductions in total body fat seem more important in inducing changes in free oestradiol, SHBG and leptin, than that in abdominal fat. However, for the inflammatory marker hsCRP and the sex hormone free testosterone, reduction in abdominal fat seems more important.

Body fat produces several markers of inflammation and adipokines (Hassan et al. 2012, van Kruijsdijk et al. 2009). Metabolic risk profiles may vary between individuals with equal amounts of total body fat. Metabolically unhealthy patients appear to have more visceral fat tissue (Despres et al. 2008). Abdominal fat, especially intraabdominal, is thought to be more metabolically active and harmful (Jensen 2008, Umemura et al. 2014).

Several cross-sectional studies have found associations between CT- or MRI-assessed subcutaneous and intraabdominal fat and elevated markers of inflammation and adipokines, also independent of total body fat (Park et al. 2004, Vega et al. 2006, Pou et al. 2007, Ritland et al. 2008, Jain et al. 2009, Turer et al. 2011, Neeland et al. 2013, Ryan et al. 2014). In the Framingham Heart Study, crosssectional associations were found for both CT-measured subcutaneous and intra-abdominal fat and markers of inflammation including CRP, IL-6 (Pou et al. 2007) and adiponectin (Jain et al. 2009). Another cross-sectional study in 1200 obese subjects found that subcutaneous and intra-abdominal fat, measured by MRI, were associated with adiponectin, CRP and leptin. In general, there was no evidence for a particular abdominal fat depot being of more importance for markers of inflammation (Neeland et al. 2013). In our study, changes in abdominal fat were also associated with changes in hsCRP, leptin and IL-6. For IL-6, this association is weak and not statistically significant, and the proportion of variance of change in IL-6 explained by changes in intra-abdominal fat was only $2 \%$. For changes in adiponectin levels, we found that these were more strongly associated with changes in total body fat compared to abdominal fat. However, as with IL-6, the associations of change in adiponectin levels with total body fat changes were also weak and not statistically significant, and the proportion of variance explained by changes in total body fat was only $2 \%$. It is possible that effects on IL- 6 and adiponectin levels take longer than 16 weeks. Another potential explanation is that more weight loss is necessary to induce effects on these biomarkers in women. For adiponectin, it might also be that levels are not as responsive to weight loss in women compared to that in men (Ma et al. 2016).

Sex hormones are associated with an increased risk of breast cancer (Kaaks et al. 2001, Key et al. 2002). After menopause, the main source of sex hormones is fat tissue (Siiteri 1987). Excess abdominal fat could independently increase bioavailable sex hormone levels as it is associated with hyperinsulinaemia that inhibits SHBG production (Haffner et al. 1991, Kaye et al. 1991).

Results from cross-sectional studies investigating the associations between sex hormones and abdominal fat (mostly measured by DEXA or waist circumference) in postmenopausal women are mixed (Bezemer et al. 2005, Mahabir et al. 2006, Baglietto et al. 2009, Liedtke et al. 2012). However, it is known that the relation can also be the other way round: menopausal-related change in hormone status may also influence the fat distribution.

To our knowledge, only two longitudinal intervention studies explored the role of changes in abdominal fat measured by CT in relation between exercise-induced weight loss and sex hormones in healthy postmenopausal women (McTiernan et al. 2004, Frank et al. 2005, Friedenreich et al. 2011). Although results of other studies are difficult to compare to that of ours, their findings also suggest that total body fat plays a more important role in determining sex hormone levels than specifically abdominal fat.

Strengths of our study include the relatively large sample size and objective measurements of total body fat (with DEXA), as well as intra-abdominal and subcutaneous abdominal fat with MRI of the abdomen, i.e. by DEXA and MRI (Shuster et al. 2012) Another strength is the use of two longitudinal measurement of both the fat depots and the biomarkers. For the measurement of sex hormones, we used a highly valid method, i.e. the LC-MS method (Blair 2010). Furthermore, subcutaneous and intra-abdominal fat quantifications were obtained from three MRI slices at different levels of the abdomen, instead of single slice analysis which is often used.

A limitation to our study is the observational but inevitable nature of these analyses, which hampers causal inferences on the role of different fat depots and risk of breast cancer. However, these longitudinal results build upon cross-sectional findings from previous studies in the literature. In particular, the inevitable correlations between changes in the three fat measures restricts the possibility of drawing firm conclusions about which fat measures are causally associated with which biomarkers. Another inevitable limitation of comparing the effects of the different fat locations (total body fat vs abdominal fat) is the fact that they are measured in different units and, thereby, different risk of measurement error.

In conclusion, we found that loss of fat at different body locations in healthy overweight postmenopausal

Published by Bioscientifica Ltd 
women was associated with changes in different types of biomarkers, known to be related to risk of breast cancer. None of the changes in fat depots was significantly associated with changes in IL- 6 and adiponectin. A change in total body fat, more than a change in abdominal fat, seemed to be associated with changes in free oestradiol, SHGB and leptin. However, changes in the abdominal fat seemed stronger compared with changes in hsCRPand free testosterone.

\section{Supplementary data}

This is linked to the online version of the paper at http://dx.doi.org/10.1530/ ERC-16-0490.

\section{Declaration of interest}

The authors declare that they have no competing interests.

\section{Funding}

This work was supported by the Dutch Cancer Society [KWF: UU 20104843] and the Dutch Pink Ribbon Foundation [PR110032, PR110039]. The support from the sponsors was unconditional, and the data collection, design, management, analysis, interpretation and reporting were performed without their interference. The role of the sponsors was limited to approving the scientific proposal of the study, covering salary costs of study personnel, costs for the data collection and costs for biochemical analyses. The authors have no non-financial competing interests to disclose.

\section{Author contributions}

Authors $P P_{1} J S$, and $E M$ were involved in the conception of the study. $P P, J S, W G$, and $E M$ were involved in the design. $P P, J S, W G$, and $E M$ participated in the management and coordination of the study. W G, J P, $M S, W V$, and $E M$ were involved in the data collection. W G, J S, J P, A M, $P P, S E, R S$ and $E M$ analysed the data.

W G, J S, J P, A M, P P, and E M drafted the manuscript. All authors have been involved in the interpretation of data and have critically revised the content of the manuscript. All authors have read and approved the final manuscript.

\section{Acknowledgements}

The authors would like to acknowledge the following people who have collected data or contributed to the study: Marloes van Beurden, Ria Bouwhuis, Bram Dijker, Gerry van Hemert, Manon de Leeuw, Marjon van der Meer, Karen Menninga, Joke Metselaar, Fien Stern, Lizeth Vendrig, Lydeke Zwart (Julius Center, Utrecht). Silvia Achterberg, Renate Bloemen, Willemien Boersma, Mirjam Floor, Petra Hemeltjen, Veronique Sauerwald (Medical Spectrum Twente, Enschede). Roelof Peters, Jolanda Spruit (HU University of Applied Sciences Utrecht). Brian G Keevil, Laura J Owen (Biochemistry Department, UHSM). Dick van Rumpt, Rick Ruckert, Holger de Wolf, Carolien Huetink, Laura Berends (SHO laboratory Velp). Furthermore, the authors would like to thank all the study participants and the participating dietitians, physiotherapists and Nordic walking instructors in the vicinities of Utrecht and Enschede.

\section{References}

Arner P 1998 Not all fat is alike. Lancet 351 1301-1302. (doi:10.1016/ S0140-6736(05)79052-8)

Baglietto L, English DR, Hopper JL, MacInnis RJ, Morris HA, Tilley WD, Krishnan K, \&Giles GG 2009 Circulating steroid hormone concentrations in postmenopausal women in relation to body size and composition. Breast Cancer Research and Treatment 115 171-179. (doi:10.1007/s10549-008-0069-3)

Bezemer ID, Rinaldi S, Dossus L, Gils CH, Peeters PH, Noord PA, Buenode-Mesquita HB, Johnsen SP, Overvad K, Olsen A et al. 2005 C-peptide, IGF-I, sex-steroid hormones and adiposity: a crosssectional study in healthy women within the European Prospective Investigation into Cancer and Nutrition (EPIC). Cancer Causes Control 16 561-572.

Bjorntorp P 1997 Obesity. Lancet 350 423-426.

Blair IA 2010 Analysis of estrogens in serum and plasma from postmenopausal women: past present, and future. Steroids $\mathbf{7 5}$ 297-306.

Cepeda-Valery B, Pressman GS, Figueredo VM, \&Romero-Corral A 2011 Impact of obesity on total and cardiovascular mortality-fat or fiction? Nature Reviews Cardiology 8 233-237. (doi:10.1038/ nrcardio.2010.209)

Despres JP, Lemieux I, Bergeron J, Pibarot P, Mathieu P, Larose E, RodesCabau J, Bertrand OF, \&Poirier P 2008 Abdominal obesity and the metabolic syndrome: contribution to global cardiometabolic risk. Arterioscler. Thrombosis and Vascular Biology 28 1039-1049.

Dixon WT 1984 Simple proton spectroscopic imaging. Radiology 153 189-194.

Frank LL, Sorensen BE, Yasui Y, Tworoger SS, Schwartz RS, Ulrich CM, Irwin ML, Rudolph RE, Rajan KB, Stanczyk F et al. 2005 Effects of exercise on metabolic risk variables in overweight postmenopausal women: a randomized clinical trial. Obesity Research 13 615-625. (doi:10.1038/oby.2005.66)

Friedenreich CM, Neilson HK, Woolcott CG, Wang Q, Yasui Y, Brant RF, Stanczyk FZ, Campbell KL, \&Courneya KS 2011 Mediators and moderators of the effects of a year-long exercise intervention on endogenous sex hormones in postmenopausal women. Cancer Causes Control 22 1365-1373. (doi:10.1007/s10552-011-9809-5)

Friedenreich CM, Woolcott CG, McTiernan A, Ballard-Barbash R, Brant RF, Stanczyk FZ, Terry T, Boyd NF, Yaffe MJ, Irwin ML et al. 2010 Alberta physical activity and breast cancer prevention trial: sex hormone changes in a year-long exercise intervention among postmenopausal women. Journal of Clinical Oncology 281458 (doi:10.1200/JCO.2009.24.9557)

Guo YZ, Pan L, Du CJ, Ren DQ, \&Xie XM 2013 Association between C-reactive protein and risk of cancer: a meta-analysis of prospective cohort studies. Asian Pacific Journal of Cancer Prevention 14 243-248.

Haffner SM, Katz MS, \& Dunn JF 1991 Increased upper body and overall adiposity is associated with decreased sex hormone binding globulin in postmenopausal women. International Journal of Obesity $\mathbf{1 5}$ $471-478$.

Handelsman DJ \& Wartofsky L 2013 Requirement for mass spectrometry sex steroid assays in the Journal of Clinical Endocrinology and Metabolism. Journal of Clinical Endocrinology and Metabolism 98 3971-3973. (doi:10.1210/jc.2013-3375)

Hassan M, Latif N, \& Yacoub M 2012 Adipose tissue: friend or foe? Nature Reviews Cardiology 9 689-702. (doi:10.1038/ nrcardio.2012.148)

Jain SH, Massaro JM, Hoffmann U, Rosito GA, Vasan RS, Raji A, O’Donnell CJ, Meigs JB, \& Fox CS 2009 Cross-sectional associations between abdominal and thoracic adipose tissue compartments and adiponectin and resistin in the Framingham Heart Study. Diabetes Care 32 903-908. (doi:10.2337/dc08-1733)
(C) 2017 Society for Endocrinology Printed in Great Britain
Published by Bioscientifica Ltd 
Jensen MD 2008 Role of body fat distribution and the metabolic complications of obesity. Journal of Clinical Endocrinology and Metabolism 93 S57-S63. (doi:10.1210/jc.2008-1585)

Kaaks R \& Lukanova A 2001 Energy balance and cancer: the role of insulin and insulin-like growth factor-I. Proceedings of The Nutrition Society Journal 60 91-106. (doi:10.1079/PNS200070)

Kaaks R, Rinaldi S, Key TJ, Berrino F, Peeters PH, Biessy C, Dossus L, Lukanova A, Bingham S, Khaw KT et al. 2005 Postmenopausal serum androgens, oestrogens and breast cancer risk: the European prospective investigation into cancer and nutrition. Endocrine-Related Cancer 12 1071-1082. (doi:10.1677/erc.1.01038)

Kaye SA, Folsom AR, Soler JT, Prineas RJ, \& Potter JD 1991 Associations of body mass and fat distribution with sex hormone concentrations in postmenopausal women. International Journal of Epidemiology 20 151-156. (doi:10.1093/ije/20.1.151)

Key T, Appleby P, Barnes I, \& Reeves G 2002 Endogenous sex hormones and breast cancer in postmenopausal women: reanalysis of nine prospective studies. Journal of the National Cancer Institute 94 606-616. (doi:10.1093/jnci/94.8.606)

Lee CM, Huxley RR, Wildman RP, \& Woodward M 2008 Indices of abdominal obesity are better discriminators of cardiovascular risk factors than BMI: a meta-analysis. Journal of Clinical Epidemiology $6 \mathbf{1}$ 646- (doi:10.1016/j.jclinepi.2007.08.012)

Liedtke S, Schmidt ME, Vrieling A, Lukanova A, Becker S, Kaaks R, Zaineddin AK, Buck K, Benner A, Chang-Claude J et al. 2012 Postmenopausal sex hormones in relation to body fat distribution. Obesity 20 1088-1095.

Ma W, Huang T, Wang M, Zheng Y, Wang T, Heianza Y, Sun D, Smith SR, Bray GA, Sacks FM et al. 2016 Two-year changes in circulating adiponectin, ectopic fat distribution and body composition in response to weight-loss diets: the POUNDS Lost Trial. International Journal of Obesity 40 1723-1729.

Macis D, Guerrieri-Gonzaga A, \& Gandini S 2014 Circulating adiponectin and breast cancer risk: a systematic review and metaanalysis. International Journal of Epidemiology 43 1226-1236. (doi:10.1093/ije/dyu088)

Mahabir S, Baer DJ, Johnson LL, Hartman TJ, Dorgan JF, Campbell WS, Clevidence BA, \& Taylor PR 2006 Usefulness of body mass index as a sufficient adiposity measurement for sex hormone concentration associations in postmenopausal women. Cancer Epidemiology, Biomarkers \& Prevention 15 2502-2507.

McTiernan A, Tworoger SS, Rajan KB, Yasui Y, Sorenson B, Ulrich CM, Chubak J, Stanczyk FZ, Bowen D, Irwin ML et al. 2004 Effect of exercise on serum androgens in postmenopausal women: a 12-month randomized clinical trial. Cancer Epidemiology, Biomarkers \& Prevention 13 1099-1105.

McTiernan A, Tworoger SS, Ulrich CM, Yasui Y, Irwin ML, Rajan KB, Sorensen B, Rudolph RE, Bowen D, Stanczyk FZ et al. 2004 Effect of exercise on serum estrogens in postmenopausal women: a 12-month randomized clinical trial. Cancer Research 64 2923-2928. (doi:10.1158/0008-5472.CAN-03-3393)

Monninkhof EM, Velthuis MJ, Peeters PH, Twisk J, \& Schuit AJ 2009 The effect of exercise on postmenopausal sex hormone levels and the role of body fat: a randomized controlled trial. Journal of Clinical Oncology 27 4492-4499. (doi:10.1200/JCO.2008.19.7459)

Neeland IJ, Ayers CR, Rohatgi AK, Turer AT, Berry JD, Das SR, Vega GL, Khera A, McGuire DK, Grundy SM et al. 2013 Associations of visceral and abdominal subcutaneous adipose tissue with markers of cardiac and metabolic risk in obese adults. Obesity 21 E439-E447.

Niu J, Jiang L, Guo W, Shao L, Liu Y, \&Wang L 2013 The association between leptin level and breast cancer: a meta-analysis. PLoS One $\mathbf{8}$ e67349. (doi:10.1371/journal.pone.0067349)

Owen LJ, Wu FC, \& Keevil BG 2014 A rapid direct assay for the routine measurement of oestradiol and oestrone by liquid chromatography tandem mass spectrometry. Annals of Clinical Biochemistry $\mathbf{5 1}$ 360-367. (doi:10.1177/0004563213501478)
Park KG, Park KS, Kim MJ, Kim HS, Suh YS, Ahn JD, Park KK, Chang YC, \& Lee IK 2004 Relationship between serum adiponectin and leptin concentrations and body fat distribution. Diabetes Research and Clinical Practice 63 135-142. (doi:10.1016/j. diabres.2003.09.010)

Pischon T, Boeing H, Hoffmann K, Bergmann M, Schulze MB, Overvad K, van der Schouw YT, Spencer E, Moons KG, Tjonneland A et al. 2008 General and abdominal adiposity and risk of death in Europe. New England Journal of Medicine 3592105 (doi:10.1056/NEJMoa0801891)

Positano V, Cusi K, Santarelli MF, Sironi A, Petz R, Defronzo R, Landini L, \&Gastaldelli A 2008 Automatic correction of intensity inhomogeneities improves unsupervised assessment of abdominal fat by MRI. Journal of Magnetic Resonance Imaging 28 403-410. (doi:10.1002/jmri.21448)

Pou KM, Massaro JM, Hoffmann U, Vasan RS, Maurovich-Horvat P, Larson MG, Keaney JF, Jr., Meigs JB, Lipinska I, Kathiresan S et al. 2007 Visceral and subcutaneous adipose tissue volumes are cross-sectionally related to markers of inflammation and oxidative stress: the Framingham Heart Study. Circulation 116 1234-1241.

Rinaldi S, Geay A, Dechaud H, Biessy C, Zeleniuch-Jacquotte A, Akhmedkhanov A, Shore RE, Riboli E, Toniolo P, \& Kaaks R 2002 Validity of free testosterone and free estradiol determinations in serum samples from postmenopausal women by theoretical calculations. Cancer Epidemiology, Biomarkers \& Prevention 11 1065-1071.

Ritchie SA \& Connell JM 2007 The link between abdominal obesity, metabolic syndrome and cardiovascular disease. Nutrition, Metabolism and Cardiovascular Diseases 17 319-326. (doi:10.1016/j. numecd.2006.07.005)

Ritland LM, Alekel DL, Matvienko OA, Hanson KB, Stewart JW, Hanson LN, Reddy MB, Van L, \& Genschel U 2008 Centrally located body fat is related to appetitive hormones in healthy postmenopausal women. European Journal of Endocrinology 158 889-897. (doi:10.1530/EJE-07-0836)

Ryan AS, Ge S, Blumenthal JB, Serra MC, Prior SJ, \&Goldberg AP 2014 Aerobic exercise and weight loss reduce vascular markers of inflammation and improve insulin sensitivity in obese women. Journal of the American Geriatrics Society 62 607-614.

Shuster A, Patlas M, Pinthus JH, \& Mourtzakis M 2012 The clinical importance of visceral adiposity: a critical review of methods for visceral adipose tissue analysis. British Journal of Radiology 85 1-10. (doi:10.1259/bjr/38447238)

Siiteri PK 1987 Adipose tissue as a source of hormones. American Journal of Clinical Nutrition 45 277-282.

Tchernof A \& Despres JP 2013 Pathophysiology of human visceral obesity: an update. Physiological Reviews 93 359-404. (doi:10.1152/ physrev.00033.2011)

Thienpont LM, Van UK, Blincko S, Ramsay CS, Xie H, Doss RC, Keevil BG, Owen LJ, Rockwood AL, Kushnir MM et al. 2008 State-ofthe-art of serum testosterone measurement by isotope dilution-liquid chromatography-tandem mass spectrometry. Clinical Chemistry $\mathbf{5 4}$ 1290-1297.

Turer AT, Khera A, Ayers CR, Turer CB, Grundy SM, Vega GL, \& Scherer PE 2011 Adipose tissue mass and location affect circulating adiponectin levels. Diabetologia 54 2515-2524.

Umemura A, Sasaki A, Nitta H, Otsuka K, Suto T, \& Wakabayashi G 2014 Effects of changes in adipocyte hormones and visceral adipose tissue and the reduction of obesity-related comorbidities after laparoscopic sleeve gastrectomy in Japanese patients with severe obesity. Endocrine Journal 61 381-391. (doi:10.1507/ endocrj.EJ13-0524)

van Gemert WA, Iestra JI, Schuit AJ, May AM, Takken T, Veldhuis WB, van der PJ, Wittink H, Peeters PH, \& Monninkhof EM 2013 Design of the SHAPE-2 study: the effect of physical activity, in addition to 
weight loss, on biomarkers of postmenopausal breast cancer risk. BMC Cancer 13395.

van Gemert WA, May AM, Schuit AJ, Oosterhof BY, Peeters PH, \& Monninkhof EM 2016 Effect of weight loss with or without exercise on inflammatory markers and adipokines in postmenopausal women: the SHAPE-2 trial, a randomized controlled trial. Cancer Epidemiology, Biomarkers \& Prevention 25 799-806.

van Gemert WA, Schuit AJ, van der palen J, May AM, Iestra JA, Wittink H, Peeters PH, \& Monninkhof EM 2015 Effect of weight loss, with or without exercise, on body composition and sex hormones in postmenopausal women: the SHAPE-2 trial. Breast Cancer Research $\mathbf{1 7} 120$. van Kruijsdijk RC, van der WE, \& Visseren FL 2009 Obesity and cancer: the role of dysfunctional adipose tissue. Cancer Epidemiology, Biomarkers \& Prevention 18 2569-2578.

Vega GL, ms-Huet B, Peshock R, Willett D, Shah B, \& Grundy SM 2006 Influence of body fat content and distribution on variation in metabolic risk. Journal of Clinical Endocrinology and Metabolism 91 4459-4466.

World Cancer Research Fund/American Institute for Cancer Research 2010 Continuous Update Project Report. Breast Cancer 2010 Report: Food, Nutrition, Physical Activity, and the Prevention of Breast Cancer. Washington DC, USA: WCRF/AICR. (available at: http://wcrf.org/ sites/default/files/Breast-Cancer-2010-Report.pdf)

Received in final form 27 March 2017

Accepted 7 April 2017 